\title{
Euglycemic diabetic ketoacidosis in a Patient who had a total hysterectomy.
}

A. $\operatorname{Tan}^{1}$, V. $\mathrm{Ng}^{1}$, S. Nagarajan² . 1: Tan Tock Seng Hospital - Singapore, 2: KK Women's and Children's Hospital - Singapore

\section{Background:}

- Diabetic ketoacidosis (DKA) is characterized by hyperketonaemia with an arterial $\mathrm{pH}$ of $<7.3$ and plasma glucose levels more than $13.9 \mathrm{mmol} / \mathrm{L}(250 \mathrm{mg} / \mathrm{dl})$ [1]. Euglycemic DKA (euDKA) occurs when glucose levels are less than $16.7 \mathrm{mmol} / \mathrm{L}(300 \mathrm{mg} / \mathrm{dl})$ when first reported in 1973 by Munro et al [2], but other authors suggested a cut-off of $11.1 \mathrm{mmol} / \mathrm{L}(200 \mathrm{mg} / \mathrm{dl})[3,5]$.

- EuDKA has been described mainly in type 1 diabetes, pregnancy and with sodium glucose cotransporter 2 inhibitors. However, it is not as well recognised as an acute post operative complication in patient with Diabetes Mellitus (DM). This may result in a delay in management and life threatening complications.

\section{Case Report:}

A 54-year-old lady with history of Ischaemic heart disease and DM on basal insulin glargine 54units every morning with novorapid 12 units at mealtimes, had an uneventful Total Abdominal Hysterectomy, Bilateral Salpingo-Oophorectomy for Ovarian Carcinoma under general anaesthesia. On the $1^{\text {st }}$ post-operation day (POD) in the general ward, she developed a sinus tachycardia (of about 110 beats per minute), and was given multiple $0.9 \%$ normal saline boluses on a background of $2.5 \mathrm{Litre/day} \mathrm{infusion} \mathrm{and} \mathrm{IV} \mathrm{ceftriaxone}$ and metronidazole for likely intraabdominal sepsis.

In view of her increasing tachycardia and respiratory distress on the $3^{\text {rd }}$ POD, she was transferred to the intensive care unit. On assessment, she had sinus tachycardia $137 \mathrm{bpm}$, blood pressure 140/60mmHg, respiratory rate of 28 , oxygen saturation of $95 \%$ on room air, and a temperature of $37.6^{\circ} \mathrm{C}$. Examination revealed a tachypnoeic patient with normal lungs signs and a distended abdomen with reduced bowel sounds. She had a good urine output of $1.1-1.9 \mathrm{ml} / \mathrm{kg} / \mathrm{hr}$ over the last 3 days. Her basal insulin had been withheld as her appetite remained poor, and only 4 units insulin in total was administered over the last 3 days as her hypocount trend remained normal between 8.3 to $12.2 \mathrm{mmol} / \mathrm{dl}$.

The investigations revealed a $\mathrm{pH} 7.20 \mathrm{HCO}_{3} 8.1 \mathrm{mmol} / \mathrm{L} \mathrm{BE}-18.2$ $\mathrm{PaCO}_{2} 21 \mathrm{mmHg}, \mathrm{PaO}_{2} 123 \mathrm{mmHg}$, corrected anion gap 19 with albumin of $24 \mathrm{mmol} / \mathrm{L}$, lactate $0.9 \mathrm{mmol} / \mathrm{L}$, ketones was $3.4 \mathrm{mmol} / \mathrm{L}$, with normal glucose of $9.9 \mathrm{mmol} / \mathrm{L}$, confirming the diagnosis of euglycemic diabetic ketoacidosis. The serum sodium was 131, chloride $108 \mathrm{mmol} / \mathrm{L}$, delta ratio 0.45 which suggested a concomitant normal anion gap metabolic acidosis. The total white count 18.66 x 109/L and Procalcitonin $4.82 \mathrm{ug} / \mathrm{L}$, suggesting sepsis. Abdominal X rays showed dilated small bowel suggesting post-operative ileus. A CT Pulmonary Angiogram ruled out a pneumonia, pulmonary embolism and congestive cardiac failure as causes.

In the ICU, insulin therapy was commenced at 3 units/hour with a $2 \mathrm{~L} /$ day of Dextrose $5 \%$ saline $0.9 \%$ maintenance solution, with lactated Ringers' given for (total 1.25L) fluid resuscitation. Antibiotic was escalated to Piperacillin-tazobactam and a nasogastric tube was inserted to decompress the stomach. Frequent monitoring ensured normoglycemia and normal electrolytes, especially serum potassium. Repeated arterial blood gases and ketones showed improvement. On $4^{\text {th }} \mathrm{POD}$, the heart rate and respiratory rate became normal with resolution of ketosis, and IV insulin regime was revised to subcutaneous insulin as recommended by the endocrine service. Oral intake was resumed and nasogastric tube was removed on the $5^{\text {th }} \mathrm{POD}$ She was transferred up to the general ward on the $6^{\text {th }}$ POD, and made good recovery to be discharged well to home on the $9^{\text {th }}$ POD with oral augmentin.

\section{Discussion:}

- DKA occurs from a state of relative insulin deficiency with elevated stress hormones triggered by numerous precipitating factors, such as sepsis, inadequate insulin therapy, poor caloric intake leading to ketoacidosis [3]. The cessation of insulin therapy in the post-operative setting could be accidental or intentional [4]. The absence of hyperglycaemia in euDKA can result from any illness, surgery, pregnancy, fasting or adequate intravenous hydration and diuresis, etc. [5, 6,]. In our patient, it was likely contributed by her poor oral intake with possible hepatic glycogen depletion, coupled with good diuresis and possible glycosuria from the intravenous hydration.

- The management of EuDKA is similar to DKA with greater attention needed to maintain normoglycemia[1].

- Intravenous insulin can be started at 0.1 units $/ \mathrm{kg} / \mathrm{hour}$ and adjusted accordingly, and then bridged to subcutaneous insulin after the resolution of ketoacidosis [1]. Hyperglycaemia is often corrected faster than ketonemia. Hence in our patient, we used a lower dose of $0.05 \mathrm{unit} / \mathrm{kg} / \mathrm{hr}$ of insulin infusion with dextrose $5 \%$ solution to maintain normoglycemia.

- To avoid hypokalaemia, insulin was stopped when serum potassium fall below $3.3 \mathrm{mmol} / \mathrm{L}$, and then corrected to 4 to $5 \mathrm{mmol} / \mathrm{L}[1]$.

- Fluid replacement should be done over 24hours to correct the estimated deficit, avoiding excess in patients with significant comorbidites. Hyperchloremic normal anion gap metabolic acidosis (NAGMA) may occur as a result of loss of ketoanions or from excessive infusion of $0.9 \%$ normal saline[1]. In our patient, we changed further fluid boluses to Lactated Ringers solution as her investigations suggested hyperchloremic NAGMA.

- Lastly, treating the precipitating cause is paramount and in our patient, her sepsis was treated with tazocin with the resumption of her basal insulin after the resolution of ketoacidosis.

\section{Learning Points:}

1. Euglycemia DKA can occur in the post-operative period and the absence of hyperglycaemia may delay the recognition and subsequent management. This condition should be suspected in an unwell patient with a low bicarbonate in the routine renal panel.

2. Type 2 Diabetics with high basal insulin should have their basal insulin restarted in the post-operative period. Early involvement of an endocrinologist will benefit the management of these patients.

\section{References:}

1. Kitabchi AE, Umpierrez GE, Murphy MB, Kreisberg RA. Hyperglycemic crises in adult patients with diabetes: a consensus statement from the American Diabetes Association. Diabetes Care. 2006;29:2739-48

2. Munro JF, Campbell IW, McCuish AC, Duncan LJP. Euglycaemic diabetic ketoacidosis. BMJ 1973;2:578-580pmid:4197425

3. Bell PM, Graham U. Euglycaemic diabetic ketoacidosis. Pract Diab Int 2008;25:106.

4. Musey VC, Lee JK, Crawford R, Klatka MA, McAdams D, Phillips LS. Diabetes in urban African-Americans. I. Cessation of insulin therapy is the major precipitating cause of diabetic ketoacidosis. Diabetes Care 1995; 18 : 483- 489.

5. Joseph F, Anderson L, Goenka N, Vora J. Starvation-induced true diabetic euglycemic ketoacidosis in severe depression. J Gen Intern Med 2009;24:129-131. Epub 2008 Oct 31.

6. Burge MR, Hardy KJ, Schade DS. Short-term fasting is a mechanism for the development of euglycemic ketoacidosis during periods of insulin deficiency. J Clin Endocrinol Metab. 1993;76:1192-1198.

Copyright @ 2017 A. Tan, V. Ng, S. Nagarajan Contact: alvin.tan3@mohh.com.sg 